\title{
TERCEIRIZAÇÃO EM SERVIÇOS DE LIMPEZA EM UMA INSTITUIÇÃO FEDERAL DE ENSINO SUPERIOR: análise da percepção de qualidade pelos funcionários
}

\author{
Renata Salvino Pujoni VILELA ${ }^{1}$ \\ Caissa Veloso e SOUSA ${ }^{2}$
}

\begin{abstract}
${ }^{1}$ Mestre em Administração de Empresas pela Faculdade Novos Horizontes. renata_Pujoni@yahoo.com.br
${ }^{2}$ Professora e Pesquisadora do Mestrado em Administração da Faculdade Novos Horizontes.

caissaveloso@yahoo.com.br
\end{abstract}

Recebido em: 15/03/2016 - Aprovado em: 28/03/2017 - Disponibilizado em: 01/07/2017

\begin{abstract}
RESUMO
Os serviços permeiam diversos aspectos da vida humana, seja ela pessoal ou profissional. Neste sentido, tanto pessoas quanto empresas privadas valem-se da prestação de serviços de terceiros com objetivos diferenciados, que vão desde a otimização do tempo até a redução nos custos de transação. Especificamente sobre o âmbito público, o Governo Federal promulgou, em setembro de 1997, a Lei 0.491, que prevê a desestatização de atividades antes prestadas pelo serviço público e consideradas não estratégicas, como é o caso dos serviços de limpeza e conservação dos ambientes de trabalho. Neste contexto, o presente artigo teve como objetivo principal analisar aspectos críticos da limpeza do ambiente de trabalho compartilhado por servidores de uma Instituição Federal de Ensino. Foram entrevistados onze servidores de carreira da instituição pesquisada. $\mathrm{O}$ estudo adotou a abordagem qualitativa e se classificou quanto aos fins como uma pesquisa descritiva. Para a coleta de dados optou-se por roteiro de entrevistas semiestruturadas. Dentre os principais resultados é possível inferir que os entrevistados tenham percepções distintas em relação à prestação dos serviços, o que, contudo, não possibilite afirmar que exista descontentamento com os serviços prestados. Apesar de se perceberem reclamações sobre a qualidade dos serviços de limpeza é possível identificar nos discursos que, ainda assim, estes atendem a um padrão de qualidade esperado.
\end{abstract}

Palavras-chave: Qualidade de serviços. Terceirizações. Marketing de serviços. Limpeza.. Serviços de Limpeza.

\begin{abstract}
Services pervade many aspects of human life, be it personal or professional . In this sense, both individuals and private companies avail themselves of the benefit of others with different objectives, ranging from optimizing the time until the reduction in transaction costs. Specifically on the public sphere, the Federal Government enacted in September 1997, Law 0491, which provides for the privatization of activities previously undertaken by the public service and not considered strategic, such as the cleaning and conservation work environments services. In this context, this paper aimed to analyze critical aspects of cleaning work environment shared by a Federal Education Institution servers. Eleven servers career research institution were interviewed. The study adopted a qualitative approach and qualified on ends as a descriptive research. For data collection was chosen script semistructured interviews. Among the main results we can infer that the respondents have different perceptions regarding the provision of services, which, however, allows not say there was dissatisfaction with the services provided. Although if they see complaints about the quality of the cleaning services you can identify the discourses that still meet these an expected standard of quality.
\end{abstract}

Keywords: Quality of services. Outsourcing. Marketing services. Cleaning. Cleaning Services.

\section{INTRODUÇÃO}

Os serviços permeiam diversos aspectos

da vida humana, seja ela pessoal ou

profissional. Utilizam-se serviços desde o nascimento até a morte, sejam eles serviços de saúde, transporte, alimentação, lazer, limpeza, telefonia, manutenção, consultoria, seguros, cartório e muitos outros milhares que permitem às pessoas, organizar e poupar 
tempo para realização de atividades prioritárias (BATESON, 2001).

O setor de serviços possui vasta participação no contexto econômico brasileiro. Em 2012, foi o único setor que obteve alta de $1,7 \%$ e sustentou o crescimento de $0,9 \%$ da economia no país, representando $68,5 \%$ do Produto Interno Bruto (PIB) brasileiro. Considerado setor fundamental para a economia nacional, tem capacidade de absorver eventuais desempregados provenientes da indústria, setor no qual apresentou redução de crescimento de $0,8 \%$ em 2013 (AGÊNCIA BRASIL, 2013).

Assim como pessoas e empresas valemse da prestação de serviços de terceiros visando otimização de tempo, não é diferente no setor público nacional. Em setembro de 1997, o Governo Federal promulgou a Lei 9.491, que prevê a desestatização de atividades antes prestadas pelo serviço público e consideradas não estratégicas. Neste sentido, a referida lei discorre da possibilidade da Administração pública envidar esforços em funções fundamentais para a nação, tais como educação, segurança e saúde, deveres do Estado (BRASIL, 1988), transferindo a terceiros atividades de apoio (BRASIL, 1997).

Os serviços de limpeza e conservação, por exemplo, podem ser terceirizados na esfera pública, considerando previsão legal de maio de 1998, Lei 9.632, anexos I e II, extinguindo cargos que não tinham destinação final, ou seja, aqueles que apóiam as atividades fundamentais da administração pública. Um dos cargos extintos é o de servente de limpeza, posto fundamental para a conservação e limpeza dos ambientes públicos, haja vista a necessidade de asseio em ambientes organizacionais, podendo ser “(...) objeto de execução indireta." (BRASIL, 1998).

Estes serviços são como serviços continuados, ou seja

Aqueles cuja interrupção possa comprometer a continuidade das atividades da Administração e cuja necessidade de contratação deva estender-se por mais de um exercício financeiro e continuamente (BRASIL, 2008).

Nesse aspecto, cabe ressaltar que a inexistência deles afeta potencialmente as atividades fins da administração pública (GARCIA, 2010). Não obstante, afeta não somente o âmbito público, mas qualquer ambiente seja ele organizacional ou não. Condições físicas adequadas no trabalho, tais como higiene, ergonomia, ventilação, entre outros interferem na produtividade das organizações (SILVA et al., 2009).

Entretanto, a possibilidade de terceirização não dispensa a responsabilidade da administração pública de fiscalizar a prestação dos serviços ora prestado por outra organização, sendo desta forma necessária avaliação periódica dos níveis de qualidade da prestação do serviço terceirizado, agora como 
função exógena à instituição pública (BRASIL, 1993)

Sendo a qualidade um diferencial competitivo das empresas da atualidade, conforme Mainardes, Lourenço e Tontini (2010), o setor público deve buscar empresas terceirizadas que observem esse conceito.

O termo "qualidade" já foi e continua sendo muito utilizado em empresas do ramo industrial, que necessitam de controle rigoroso da qualidade dos bens produzidos. Entretanto, a avaliação da qualidade no setor de serviço deve ser realizada de maneira diferente daquele utilizado nas indústrias, ou seja, onde existe interação com o usuário (MIGUEL et al., 2011).

A Instituição pesquisada neste trabalho constitui uma autarquia federal da área de ensino, sujeita às legislações existentes e, partindo do princípio da legalidade que prevê que o serviço público só pode realizar aquilo que foi autorizado em lei (BRASIL, 1999), a instituição vale-se da terceirização de serviços de limpeza e conservação prevista na Lei 9.632, de maio de 1998. Por meio de licitação, esse serviço é contratado pela administração pública.

É neste contexto que se fundamenta o presente estudo e emerge a questão que norteia a pesquisa: Como se configuram as percepções dos servidores técnicos administrativos lotados no do Campus I da organização quanto à qualidade dos serviços de limpeza e conservação prestados por uma empresa terceirizada?

Como objetivo geral pretendeu-se analisar aspectos críticos da limpeza do ambiente de trabalho destes servidores. De forma mais específica pretendeu-se: a) analisar o impacto causado pela atividade terceirizada de limpeza; b) identificar aspectos satisfatórios e insatisfatórios do serviço prestado.

\section{REFERENCIAL TEÓRICO}

Essa seção apresenta a revisão literária sobre o tema marketing de serviços, além de abordar aspectos da qualidade em serviços e terceirização no setor público.

\subsection{Marketing de Serviços}

Segundo Lovelock e Wright (2003, p.5), o setor de serviços é composto pela "parte da economia de uma nação representada por serviços de todos os tipos, incluindo os oferecidos por organizações públicas e sem fins lucrativos" e, conforme afirma Churchill Jr. e Peter (2003), este setor tem apresentado crescimento importante nas três últimas décadas. Mas como diferenciar bens e serviços?

Para Zeithaml e Bitner (2003), os serviços são constituídos por ações, processos e atuações. Hoffman et al. (2009, p.6) os definem como "ações, esforços ou 
desempenhos." Neste mesmo entendimento e enfatizando a dificuldade de se definir um serviço ou bem puro. Segundo Bateson e Hoffman (2001), na maioria das vezes produtos oferecem algum tipo de serviço, desde os mais simples, como por exemplo, os serviços de entrega.

O Marketing de serviços e o Marketing de bens possuem semelhanças, pois ambos são destinados a oferecer valor aos clientes nas relações de troca (CHURCHILL JR.; PETER, 2003). Contudo, algumas características essenciais diferenciais bens e serviços, o que impactará nas ações de Marketing traçada pelas organizações. São estas características: a tangibilidade e a intangibilidade; a divisibilidade e a indivisibilidade; a invariabilidade e a variabilidade; a imperecibilidade e a percecibilidade (KOTLER; HAYES; BLOOM, 2002).

A intangibilidade constitui um elemento importante na caracterização dos serviços. Zeithaml e Bitner (2009) e Hoffman et al. (2009) afirmam ser esta a diferença mais básica e universalmente citada, sendo a principal diferença entre bens e serviços. Para Churchill Jr. e Peter (2003), a intangibilidade faz com que o cliente possua apenas lembranças ou experiências de resultados passados para comparar os serviços. Não obstante, já se tratando de bens, os clientes possuem o objeto físico, que pode ser usado, revendido, doado, etc.
Outro aspecto relevante é a perecibilidade, ou seja, serviços são perecivies, se perdem no tempo, sua não utilização implica em perda, como por exemplo um horário agendado com um dentista. Caso o paciente se atrase ou se esqueça da consulta, aquele serviço não será prestado. Ao contrário, o bem pode ser estocado e utilizado oportunamente. (CHURCHILL JR.; PETER, 2003).

Com os serviços vem também a figura de quem os presta. Essa característica é denominada inseparabilidade. Por exemplo, uma prestação de serviço de cirurgia plástica, pintor, consultor sem a pessoa o realizando o serviço inexiste. (CHURCHILL; PETER, 2003). Hoffman et al. (2009, p.36) relatam ser esta a mais intrigante das características de serviço, haja vista as "interconexões entre o provedor de serviços, o cliente que recebe o serviço e outros clientes que compartilham a mesma experiência." Focando em bens, esse aspecto não se evidencia, já que "bens normalmente são produzidos por determinadas pessoas e vendidos por outras"(CHURCHILL JR.; PETER, 2003, p.293).

$\mathrm{O}$ quinto aspecto de serviços relatado é o esforço do Cliente, que em serviços podem participar na sua produção, ou estar ciente da sua produção. Todavia do ponto de vista do bem, o cliente está limitado na sua mera aquisição. 
Por fim, o último aspecto que diferencia bens e serviços, perpassa a uniformidade, termo utilizado pelos autores Churchill e Peter (2003) e Zeithaml e Bitner (2003), que o definem como heterogeneidade.

Para Churchill e Peter (2003), uniformidade refere-se à variação da qualidade de serviço prestado, podendo ocorrerem falhas em sua execução. Outro fator que interfere é a possibilidade de personalização, ou seja, adequação do serviço ao gosto do cliente. Comungando do mesmo pensamento, Zeitham e Bitner (2003, p. 37) relatam que como serviços são prestados por pessoas "nunca serão os mesmos". Lembram ainda que os clientes nem sempre são exatamente os mesmos e cada serviço ocorrerá de maneira particular.

Na seção que segue trata-se do aspecto da qualidade em serviços.

\subsection{Qualidade em serviços}

Para Garcia (2010) reduzir custos e trabalhar de forma eficiente tem sido de importante para empresas modernas, e, ademais, a partir das décadas de 1980 e 1990, a necessidade da qualidade em serviço continuou a revolucionar essas empresas de modo que buscassem satisfazer desejos e necessidades criando valor para os clientes. Entretanto, como já relatado, serviços são heterogêneos, conforme definição de Zeithaml e Bitner (2003), e seu desempenho pode ser relativamente diferente de empresa para empresa e também de cliente para cliente.

A qualidade dos bens é mais facilmente percebida por meio de características técnicas, especificações detalhadas, entretanto, como serviços são séries de processos cuja produção e consumo não são separados, a percepção do cliente torna-se extremamente complexa (GRÖNROOS, 2004).

Segundo o autor (p. 85), a definição para qualidade de serviço é "qualquer coisa que o cliente perceba que ela seja", ele o percebe em um sentido muito mais amplo e outros aspectos além do técnico, dominando experiências de qualidade. Já para Lovelock e Wright (2003, p.22) a qualidade dos serviços compreende "o grau em que um serviço satisfaz os clientes ao atender suas necessidades, desejos e expectativas." Ou seja, são avaliações cognitivas de prazo longo em relação à entrega de um serviço fornecido por uma empresa.

Clientes, em geral, possuem expectativas acerca dos serviços que contratam. Eles comparam a qualidade do serviço por meio de percepções de desempenho dos prestadores. Avaliam também seus "níveis de satisfação ou insatisfação depois de cada encontro e utilizam essa informação para atualizar sua percepções da qualidade do serviço" (LOVELOCK; WRIGHT, 2003, p.106). 
Então, "descobrir o que os clientes esperam é essencial para proporcionar qualidade em serviços" (ZEITHAML; BITNER，2003, p115). Existem, neste contexto, dois níveis de expectativas: o serviço desejado e o serviço adequado. As autoras relatam que a expectativa é espelho dos desejos e crenças de seu atingimento.

Definem serviço adequado como a expectativa mínima tolerável; já o serviço desejado é aquele que o cliente desejaria receber, ou seja, o que deveria ser. (ZEITHAML; BITNER, 2003).

Por conseguinte, denomina-se zona de tolerância a variação entre serviço desejado e serviço adequado, conforme FIG. 2

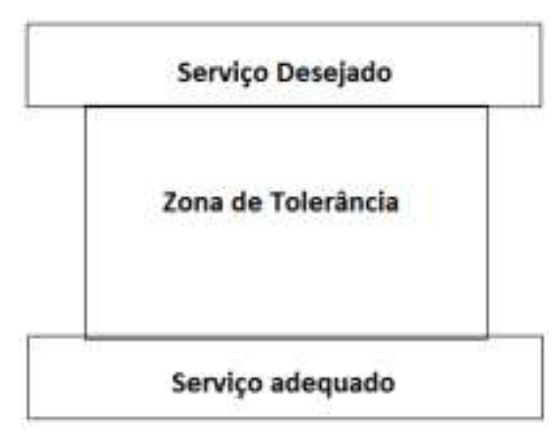

Figura 2 - Níveis duais de expectativas de clientes

Fonte: Zeithaml e Bitner (2003, p.69)

A percepção do cliente pode oscilar entre os níveis desejado e adequado dependendo de suas expectativas; essa zona pode se contrair ou se expandir. (ZEITHAML; BITNER, 2003, p.69). Caso os serviços não atinjam o nível de serviço adequado haverá frustração do consumidor e a percepção de qualidade será abalada. Por outro lado, se o desempenho dos serviços ultrapassar o nível de serviço desejado o cliente será surpreendido agradavelmente.

Neste mesmo sentido, Lovelock e Wright (2003) reafirmam a existência de expectativa por parte dos clientes que baseados em necessidades particulares e experiências passadas buscam determinado serviço, e introduzem neste contexto o nível de serviço percebido. Dependendo do que era previsto de ser fornecido o cliente pode ficar satisfeito ou não.

Já Grönroos (2004, p.85) relata que a qualidade de um serviço percebida pelos clientes também tem duas dimensões: "dimensão técnica ou resultado" e "dimensão funcional ou relacionada ao processo". A primeira dimensão, qualidade técnica é o 'que' o cliente recebe, ou seja o, resultado. A segunda, qualidade funcional, ou o 'como' o cliente recebe está ligada ao modo como os momentos da verdade dos encontros em si acontecem. (GRONROOS, 2004)

Clientes tem tolerância acerca do serviço recebido. A tolerância é relativa e depende de variados fatores. Zeithaml e Bitner (2003) descrevem que
As expectativas [de serviços] são formadas por diversos fatores incontroláveis, desde a experiência dos clientes com outras empresas e sua propaganda, até o estado psicológico dos clientes no momento da prestação do serviço. Falando de forma clara, o que os clientes esperam é sempre algo tão diverso quanto sua educação, seus valores e suas experiências. A mesma 
peça de propaganda divulga um serviço pessoal para uma pessoa pode estar dando a entender a uma outra que o anunciante acaba de prometer mais do que realmente pode executar (ZEITHAML; BITNER, 2003, p.71).

Eleutério e Souza (2002) afirmam que uma forma de administrar a qualidade de um serviço prestado é considerá-la do ponto de vista dos clientes. Os clientes escolhem produtos e serviços comparando suas percepções existentes do serviço recebido com aquele serviço esperado, ou seja, qualidade do serviço percebida (GRÖNROOS, 2004).

Para Zeithalm, Parassuraman e Berry (1991), uma boa qualidade é decorrente de superação de expectativas de clientes. As autoras ressaltam que não basta entender a relevância de fornecer serviços com excelente qualidade, mas na verdade é preciso que haja um processo contínuo de monitoração das percepções dos clientes sobre a qualidade dos serviços. Assim se faz possível identificar as causas das discrepâncias encontradas e permitindo adotar mecanismos adequados para a melhoria.

Lovelock e Wright (2003) apresentam cinco dimensões da qualidade. Pelas quais os clientes julgam a qualidade do serviço. São elas: confiabilidade, tangibilidade, sensibilidade, segurança e empatia. A seguir, o QUADRO 3 resume cada uma delas
Quadro 3 - Cinco Dimensões da

Qualidade

\begin{tabular}{|c|c|}
\hline CONFIABILIDADE & $\begin{array}{c}\text { A empresa é } \\
\text { confiável no fornecimento de } \\
\text { serviço conforme prometido, } \\
\text { no curso do tempo? }\end{array}$ \\
\hline TANGIVEIS & Como são as \\
instalações físicas, \\
equipamento, pessoal e \\
material de comunicação do \\
fornecedor do serviço?
\end{tabular}

Fonte: Lovelock, Wright (2003, p. 109)

Stefano (2009) aborda que qualidade é imprescindível para qualquer que seja a empresa, atuando em diferentes tipos de negócio. Conhecer a percepção dos clientes internos (funcionários) e externos (clientes), em relação à qualidade do serviço prestado pode ser o início de desenvolvimento de melhorias na atuação.

Ademais, para garantir a qualidade em serviços aliada à terceirização de serviços dentro da empresa, é necessária ampla fiscalização por parte dos gestores, que no caso de terceirização na esfera pública é 
requerida pela Lei 8.666/93, Licitações e Contratos (BRASIL, 1993).

\subsection{Terceirização no serviço público}

$\mathrm{Na}$ terceirização há a relação entre duas ou mais empresas na qual o trabalho é realizado por uma empresa, mas contratado de maneira imediata por outra. Independente da terceirização se concretizar em empresa pública, privada ou fundacional sua definição não é alterada, afirma a autora. Ademais utiliza o termo subcontratação como sinônimo de terceirização (MARCELINO, 2007).

De acordo com Giosa (1999), terceirização é quando se contrata, por meio da prestação de serviços, empresas especializadas em atividades específicas que não são mais adequadas de serem desenvolvidas por pessoas da própria organização.

Silva (2011) explana que o Estado e a Administração Pública, embalados por movimentos neoliberalistas iniciaram $\mathbf{O}$ processo de desestatização que tem como principal objetivo a terceirização.

A terceirização no ambiente público é permitida conforme previsão legal, ou seja, Instrução Normativa $\mathrm{n}^{0} 02$ e Decreto 2.271/97 que dispõem sobre regras e diretrizes para a contratação de serviços continuados ou não.

O Art. $7^{\circ}$ da Instrução Normativa $n^{0} 02$ traz os tipos de serviços que podem ser terceirizados,
As atividades de conservação, limpeza, segurança, vigilância, transportes, informática, copeiragem, recepção, reprografia, telecomunicações e manutenção de prédios, equipamentos e instalações serão, de preferência, objeto de execução indireta (BRASIL, 2008).

A prestação de serviços que é tratada nesta Instrução não cria vínculo da Administração pública com empregados terceirizados e proíbe a relação de subordinação direta e pessoalidade no tratamento dos funcionários terceirizados. $\mathrm{Ou}$ seja o poder de mando sobre os empregados da contratada é proibido e deve ser realizado apenas por prepostos, pessoas indicadas pela empresa terceirizada (BRASIL, 2008).

Quando da licitação, deve-se observar toda a Instrução Normativa que é balizadora da contratação, ou seja, nela está prevista toda a métrica a ser utilizada para mensuração dos trabalhos a serem realizados e posteriormente remunerados. Esses contratos advindos da licitação são celebrados com vigência de 12 (doze) meses, podendo ser renovados por mais 60 (sessenta) meses, condicionados ao aceite da empresa e interesse da Administração (BRASIL, 2008).

Sendo um serviço Terceirizado, a forma de controlar a qualidade do serviço prestado é feita por meio do acompanhamento e fiscalização da execução dos contratos, conforme prevê a Instrução Normativa $\mathrm{n}^{0} 02$ de 2008

Consiste na verificação da conformidade da prestação dos serviços e da alocação dos recursos necessários, de forma a 
assegurar o perfeito cumprimento do contrato, devendo ser exercidos por um representante da Administração, especialmente designado [...] (BRASIL, 2008).

Além disso, existem medidas de produtividade que a instrução define como

Capacidade de realização de determinado volume de tarefas, em função de uma determinada rotina de execução de serviços, considerando-se os recursos humanos, materiais e tecnológicos disponibilizados, o nível de qualidade exigido e as condições do local de prestação do serviço (BRASIL, 2008).

Enfim, terceirização no serviço público não é apenas a transferência de uma atividade meio, mas sim a subcontratação de um serviço que é fiscalizado e requerido seu melhor.

$\mathrm{Na}$ próxima seção é apresentada a metodologia utilizada para alcançar os objetivos propostos.

\section{METODOLOGIA}

Esta pesquisa visou compreender aspectos da percepção pessoal de servidores técnicos administrativos trabalhadores do Campus I de uma Instituição Federal de Ensino Médio Técnico, Tecnológico e Superior, com foco na qualidade dos serviços de limpeza terceirizados. Trata-se de uma abordagem qualitativa, devido a subjetividade proposta na análise. Quanto aos fins a pesquisa se caracterizou como descritiva. Para a coleta de dados optou-se por um roteiro de entrevistas semiestruturadas. Assim, foi realizada uma investigação empírica com o objetivo de levantar opiniões acerca da percepção destes funcionários.

Foram realizadas 11 (onze) entrevistas com servidores da Instituição, que são diretamente influenciados pelos serviços de limpeza prestados, por compartilharem o espaço físico de trabalho. $\mathrm{O}$ roteiro semiestruturado possuiu dezenove questões norteadoras, com intuito de manter-se o foco na percepção dos servidores quanto ao serviço de limpeza, prestado por empregados terceirizados. As questões serviram de orientação e foram expandidas quando necessário.

As entrevistas foram gravadas e transcritas na integra, a análise do conteúdo foi realizada estabelecendo-se conexões com a teoria qualidade em serviços e as respostas foram categorizadas por conteúdo das perguntas. Segundo Gil (2008), a entrevista é a técnica que apresenta maior flexibilidade, podendo ser focalizada,neste caso especifico, facilitando o retorno ao tema caso haja digressão.

\section{APRESENTAÇÃO E ANÁLISE} DOS DADOS

Nesta seção são apresentados os principais resultados obtidos, divididos em categorias propostas para a análise. 


\subsection{Percepção da Qualidade da}

\section{limpeza}

Apresentam-se a seguir dados demográficos dos entrevistados. Dentre os onze entrevistados, nove são mulheres e dois homens, as idades variam de 26 a 60 anos. A maioria é casada e possui mestrado. Indagados sobre o tempo de serviço na instituição há relatos de um servidor com mais de 20 anos de trabalho no Campus I, quatro servidores que trabalham cerca de 16 a 20 anos, outro a mais de 6 anos e menos de 10 , e outros cinco servidores com menos de 5 anos na organização.

Sete funcionários trabalham pela manhã e inicio da tarde, o restante varia entre inicio da tarde e final da noite. Essa pergunta foi inserida pois os a limpeza da instituição, normalmente inicia-se antes dos servidores chegarem para trabalhar.

Dez dos entrevistados trabalham no prédio administrativo e um no prédio escolar. A instituição é dividida em prédio escolar e prédio administrativo, entretanto a função administrativa não se limita apenas a este último. Muitos servidores atuam em salas do prédio escolar embora sua atuação tenha maior foco no atendimento ao aluno.

Os participantes foram indagados acerca da limpeza no momento em que chegam na instituição e percorrem o trajeto até seu local de trabalho. Esse trajeto varia de acordo com o local de trabalho de cada um, há uma portaria principal que leva até ao estacionamento, além do bosque, hall do prédio escolar e subsolo escolar e administrativo.

Vários servidores que trabalham pela manhã relatam que o serviço de limpeza está em processo de execução, embora reconheçam que a limpeza é feita rotineiramente, acreditam que há demanda de uma equipe maior para varrição desta área

Está justamente na fase de limpeza, estão trabalhando, já. Como eu chego mais cedo, então eles já estão no trabalho. Está mais pra limpo do que pra sujo (E1).

Normalmente esta limpo. Neste horário o pessoal está limpando, principalmente lá fora (E2).

A entrada aqui não tem condições. Mas eu vejo que é porque tem muitas árvores. $\mathrm{Na}$ época de outono até que eu acho bonito, mas fora o outono, eu acho que poderia ter uma equipe de limpeza, pra poder fazer essa limpeza do pátio (E3).

O entrevistado que trabalha no prédio escolar relata que, devido a inúmeras obras de construção, reforma e ampliação, a limpeza do percurso até sua sala é deficitário

Sujo, mais ou menos sujo. Do prédio administrativo pra cá está muito sujo. Porque fica na parte do campo e agora esta com construção e o pessoal da limpeza só vem aqui um horário no dia, ao longo do dia não vem. Aqui transitam muitos alunos e eles jogam muitas coisas no chão, só é limpo uma vez (E6).

Seguindo a discussão da qualidade da limpeza os participantes foram perguntados acerca de seu ambiente de trabalho, sua mesa, 
sua sala e se isso interfere no trabalho administrativo diário. Há diversos relatos negativos a esse respeito. Muitos funcionários percebem que ao efetuarem a limpeza, os empregados terceirizados, não a efetuam adequadamente e que por inúmeras vezes o material que foi deixado em cima da mesa não está em seu local de origem. Isso interfere no trabalho do funcionário administrativo que ao se deparar com essa situação necessita dispender tempo na reorganização de sua estação de trabalho. Foi narrado um episódio em que a sala dos servidores estava completamente desorganizada com computadores desligados da tomada, telefones inoperantes, cadeiras trocadas entre estações de trabalho e até entre setores.

Olha [tempo na fala], ultimamente a gente tem tido algumas queixas, porque tem ficado muito sujo; a sala tem ficado muito suja, algumas vezes a gente chega aqui e o material da mesa não está do jeito que a gente deixou. Teve um dia que nós chegamos e parecia que tinha passado um furacão aqui, o que eu fiquei sabendo é que eles iam limpar o chão, mas acho que não foram as meninas que limpam aqui normalmente não: computador desligado, telefone sem funcionar, cadeira fora de lugar, cadeiras que não eram nossas aqui, cadeiras que eram nossas e outro lugar, mas foi só esse dia que foi mais confuso (E2).

Pesquisador pergunta: Eles desorganizam sua mesa? Resposta: Não, isso porque eu pedi, no princípio sim, mas depois que eu fiz a solicitação que não misturasse os processos; eu procuro sempre manter com uma etiqueta (E3).

Totalmente desorganizada. Isso interfere no meu trabalho porque eu chego e tenho que organizar. Eu não localizo minhas coisas, elas ficam fora do lugar.
Atrapalha o espaço físico da mesa de trabalho. E a limpeza não é muito bem feita não, sempre está tudo sujo (E4).

Interfere. Normalmente ela limpa e tira tudo do lugar. Isso é ruim e já foi conversado. Inclusive todos reclamaram e já foi conversado, mas continua do mesmo jeito (E5).

Como visto nos relatos, alguns entrevistados afirmam que as mesas passaram a ficar organizadas após efetuarem queixas junto aos responsáveis pelos funcionários terceirizados no sentido de que ao limparem as mesas tivessem maior zelo em não misturar os processos administrativos, além disso, os funcionários passaram a adotar um sistema pessoal de organização por meio de etiquetação de documentos ficando assim, mais fácil a localização dos mesmos. Por outro lado, outro entrevistado disse que embora já tenha realizado diversas solicitações acerca do problema de desorganização da mesa, o problema persiste.

A percepção de um terceiro participante configura o desalinhamento de procedimentos adotados pelos empregados terceirizados ao relatar que caso a sua mesa esteja cheia de processos e papéis os auxiliares de serviços gerais não efetuam a limpeza, deixam para efetua-la no dia em que a estação de trabalho estiver desocupada.

Já em relação à limpeza dos banheiros os entrevistados, predominantemente, afirmam haver diferença entre a limpeza que é feita no terceiro andar do prédio 
administrativo e os demais andares. Esse aspecto chamou a atenção e foi questionado o motivo dessa diferenciação, o relato foi assim.

A limpeza do banheiro do terceiro andar, da Diretoria, é maravilhosa... A gente gostaria que o banheiro lá de baixo fosse igualzinho o da Diretoria (E11).

Embora haja diversos relatos negativos acerca da qualidade da limpeza, a percepção dos funcionários entrevistados é de que a limpeza é relativamente regular a boa, embora existam relatos de amplo descontentamento. O entrevistado E7 atribuiu uma nota de 8 a 9 em uma escala de zero a dez, escala proposta pelo próprio entrevistado. Outro entrevistado, E11, afirma que a limpeza no seu setor é deficiente, não sabe dizer se é má vontade dos terceirizados ou se é falta de cobrança dos supervisores. Diz, ainda, não efetuar reclamações por não ser sua função, mas que geralmente comenta com sua chefia e colegas de trabalho. Acredita que é responsabilidade da instituição fiscalizar e ouvir as reclamações dos servidores quanto à limpeza já que isso ajudaria a promover um espaço mais saudável. O entrevistado E11 trouxe riqueza de detalhes acerca da necessidade de limpeza em um específico setor da instituição:

Eu acho que tem que haver mais é iniciativa da instituição em sentir que tem uma coisa errada, ou então, perceber que quando a gente reclama ou pede, não é porque somos chatos, mas sim porque a gente quer melhorar a qualidade do serviço, então se você reclama que o seu setor não está sendo limpo, aquilo afeta todo mundo. É claro, estou lá vendo uma 'coisa' embaixo da minha mesa tem três meses daí você sente que pode ter um escorpião, um rato uma barata. Isso já aconteceu, rato é o que tem mais, já caiu rato na nossa cabeça. Lá no Setor A já caiu rato; rato urinou em cima das cadeiras que agente senta, em cima das mesas. Arrancaram o teto mas a gente está em uma situação que continua entrando rato; tem mal cheiro, isso ai já aconteceu, e o pior de tudo é trabalhar em um lugar e ver, depois de vinte anos, que o banheiro que é na porta do auditório da Instituição, principal lugar de recepção com a comunidade, alugado para diversos eventos, tem seu banheiro como um lixo. Mal cuidado, trocaram as torneiras esses dias pra melhor o aspecto, sabe, mas o chão fedendo, o banheiro horroroso, tiveram que abrir um pedaço da porta em cima pra poder sair o ar, então assim, está muito mal cuidado, e fica muito feio pra instituição (E11).

Essa descrição é relativamente isolada e trata-se de um setor específico, no geral, os entrevistados afirmam gostar da limpeza que é feira embora diversas reclamações terem sido percebidas pelas pesquisadoras.

\subsection{Percepção da Identificação e}

\section{Interrupções}

Todos os entrevistados afirmam reconhecer o uso do uniforme como forma de identificação dos empregados terceirizados, em relação ao uso de crachás, apenas um entrevistado afirma já ter visto funcionários terceirizados utilizando.

Os respondentes foram questionados a cerca da interrupção de seu trabalho quando efetuada a limpeza da sala, bem como se algo no serviço de limpeza o incomodaria, e ainda 
se todo esse contexto afetaria seu desempenho como profissional.

A partir dos discursos apresentados no que tange à interrupção do trabalho dos servidores técnicos administrativos surgiram algumas reclamações. Embora existam relatos de que apenas 'as vezes' interrupções ocasionadas pelo serviço de limpeza terceirizado ocorram, isso devido ao horário em que a limpeza é feita nem sempre é mesmo em que os servidores estão trabalhando, os relatos de interrupções constantes e incômodas foram mais expressivos em alguns casos. $\mathrm{O}$ entrevistado E7 relata prejuízo intelectual devido a constante interrupção

Interrompe de maneira física, pelo espaço, e de maneira intelectual também, por exemplo: para aqui, pede pra limpar ali, levanta daqui, levanta dali (E7).

$\mathrm{Na}$ percepção do entrevistado E6 o que mais lhe incomoda no serviço de limpeza é a utilização indiscriminada de panos de limpeza em diversos locais sem o devido cuidado de separação destes pelo uso. Veja o relato a seguir:

A utilização de panos me incomoda. O mesmo pano que ele utiliza para limpar o chão, é utilizado para limpar a mesa, as paredes e se bobear até no banheiro. O pano que ele utiliza pra limpar o vaso sanitário é o mesmo que ele utiliza pra limpar a pia, e neste caso, deveriam ser panos diferente, buchas diferentes, detergentes diferentes. Tudo tem que ser separado (E6).

Outro relato diz respeito aos horários de limpeza concomitantes:
Incomoda. Por exemplo: no mesmo horário eu já quis ir ao banheiro e o banheiro esta sendo limpo aqui no terceiro e no segundo andar ao mesmo tempo. Eu acho que elas deveriam revezar (E2).

Uma narração bem detalhada foi dada pelo entrevistado 4 no que diz respeito ao que mais lhe incomodaria na prestação do serviço de limpeza:

\begin{abstract}
Muitas coisas. A primeira é que não tem treinamento adequado, e outra questão é que não tem muitas pessoas pra trabalhar. A nossa limpeza é como se fosse um tapa buraco porque elas [meninas da limpeza] vem de manhã, por exemplo, a moça cuida lá da sala, pra limpar as salas e tudo, então essa questão do tamanho do espaço físico, da área que a gente tem que é muito grande [instituição], se fosse calcular proporcionalmente o número de pessoas trabalhando, é deficitário e essa questão mesmo do treinamento. A empresa contratada... [pausa] não sei como foi feito o edital de licitação, mas deveria constar treinamento, conscientização, principalmente na questão de cuidar do bem público.
\end{abstract}

Não obstante a diversas reclamações e relatos descontentes nove dos onze entrevistados afirmam que a limpeza do Campus I não afeta seu desempenho profissional, apenas dois entrevistados, garantem afetação.

\footnotetext{
Afeta porque o moveis que a gente precisa deslocar ou guardar ficam imundos (E6).

Claro que as condições de limpeza afetam o desempenho. Eu considero que é um andar bem limpinho [terceiro andar], então é bem positiva essa interferência (E1).
} 


\subsection{Percepção do Atendimento e}

\section{Cordialidade}

$\mathrm{O}$ atendimento é percebido pelos servidores como relativamente ágil e precisa ser solicitado ao representante da empresa denominado supervisor, alguns entrevistados relatam nunca ter solicitado serviços extra, enquanto outros dizem que a solicitação depende da disponibilidade dos funcionários terceirizados.

Em relação à cordialidade, os terceirizados são percebidos, do ponto de vista dos entrevistados, como cordiais e atenciosos, embora a expressão física destes seja de apatia. Esse é um aspecto levantado pelo Entrevistado E7:

Sim, são cordiais. Acredito que sim. A expressão física deles não é das melhores, acho que isso poderia melhorar. Mas temos que observar também que eles são os que menos ganham aqui na Instituição, salvo exceção de alguns mais alegres, a maioria tem expressão mais triste (E7).

Normalmente os funcionários terceirizados tem baixa escolaridade $\mathrm{e}$ conforme relato de um entrevistado, são humildes e não interagem muito com os servidores.

\subsection{Percepção das consequências da}

\section{Terceirização}

As últimas questões visaram identificar o nível de conhecimento dos servidores sobre terceirização, se sabiam que o serviço de limpeza na instituição era terceirizado, como identificavam esse fato e se acreditam que caso o serviço de limpeza fosse realizado por servidores de carreira haveria diferença na qualidade dos serviços e ainda, se já houve troca da empresa terceirizada e como o entrevistado identificou esse fato.

Todos os entrevistados dizer ter conhecimento de que o serviço de limpeza é terceirizado, isso pelo uso constante do uniforme com nome e logomarca diverso ao da instituição, pelo fato de inexistir concursos para essa ocupação, pelo fato do entrevistado trabalhar no setor responsável pela contratação da empresa terceirizada, e ainda pelas conversas entre os prestadores de serviço.

Para alguns servidores, o fato do serviço ser terceirizado garante a qualidade já que esses funcionários terceirizados podem ser amplamente cobrados pela limpeza o que não ocorreria se os serviços fossem realizados por servidores de carreira, no ponto de vista dos Entrevistado E4, o serviço seria melhor, já para os entrevistados E2 e E5 seria pior a qualidade dos serviços prestados por servidores

$\mathrm{Eu}$ acho que seria pior. Não sei sabe, porque tem gente que é contaminado. As vezes a pessoa contratada teria essa consciência que havia falado, de cuidar mais do bem público que aquele ali é um setor, ou seja, é o serviço dela, o trabalho dela. Nessa questão ai talvez, mudando 
minha resposta, ela ia cuidar melhor (E4).

Nunca parei pra pensar nisso, mas acho que sim. Há primeira vista, achei que ia ser melhor mas pensando em alguns servidores que a gente tem aqui na instituição. Eu acho que essa questão de estabilidade, as vezes, faz com que as pessoas trabalhem menos, de repente elas sendo terceirizadas, elas tem essa obrigação de cumprir, tem que cumprir porque podem acabar perdendo $\mathrm{o}$ emprego, então pensando melhor, sendo terceirizadas as chances de ser melhor o serviço é maior (E2).

Eu acho que talvez seria pior. Porque a tendência da pessoa saber que tem estabilidade, não vai ter muita cobrança. Então eu acho que terceirizado o compromisso deles é maior, porque a possibilidade deles serem dispensados é muito maior (E5).

Em relação a percepção quando há mudança de empresa, vários entrevistados afirmam que percebem a mudança pela alteração do uniforme, e que isso já ocorreu por diversas vezes ao longo dos anos que estão na organização. Um relato consegue definir os impactos causados pela mudança da empresa de limpeza, esse fato ocorre por meio de licitações:

Sim. Desde que eu entrei aqui na instituição a Empresa X estava presente, ela ganhou outra licitação, mas uma penúltima, salvo engano, ela perdeu pra uma empresa do Rio de Janeiro, Empresa $\mathrm{R}$, e houve um impacto muito significativo que a gente, não só eu, mas todos os servidores perceberam e a reclamatória foi grande. Agente desse processo de penalização, rescisão de contrato com a empresa e tudo, mas foi perceptível que o nível da outra empresa era diferente. A qualidade do serviço ficou prejudicada, pois era o que o fiscal do contrato reclamava. Foi como ele instruiu o processo penalizando a Empresa R, não havia faxina, limpador de vidros, a quantidade da rotina era bem menor. Parece empresa aventureira. E outra coisa, a quantidade de funcionários que ela coloca aqui é por estabelecimento via legislação, não é pela empresa, por metro quadrado, então é uma matemática (E7).

Predominantemente os entrevistados afirmam que mudanças ocasionam problemas iniciais, e que embora a empresa mude, as pessoas que trabalham como terceirizados na instituição costumam permanecer, entretanto, a mudança da empresa contratada gera transtornos tanto para a administração pública quanto para os terceirizados, pensar que a permanência dos funcionários facilitaria a fixação da nova empresa na instituição pelo fato deste já conhecerem os serviços é um grande equívoco.

\section{CONSIDERAÇÕES FINAIS}

O estudo realizado não teve a pretensão de generalizar, contestar ou confirmar os estudos de Marketing de serviços, na realidade, buscou-se analisar por meio de entrevistas a percepção dos servidores de uma instituição federal de ensino em relação a qualidade do serviço terceirizado de limpeza. A pesquisa propôs-se em avaliar essa percepção por meio de questionamentos semiestruturados.

Por meio deste estudo, foi possível identificar que, embora reclamem dos serviços de limpeza, a percepção geral dos servidores é de que devido a diversas 
limitações de profissionais, o serviço é a contento.

Isso é um tanto quanto contraditório, pois se há reclamações, há algo que precisa ser melhorado; a comunicação entre contratante e contratada deve ser revista a melhor atender aos anseios dos servidores que estão diuturnamente trabalhando em um ambiente insalubre.

As características dos serviços descritas por Churchill e Peter (2003), tais como relação com os clientes, perecibilidade, intangibilidade, inseparabilidade, esforço do cliente, uniformidade/heterogeneidade foram perceptíveis nos relatos dos entrevistados, principalmente o aspecto da heterogeneidade pois o serviço prestado em no terceiro andar é diferente do prestado no primeiro, variando assim, a qualidade percebida pelos servidores. Além disso o aspecto da inseparabilidade está visível no humor dos terceirizados que devido a uma serie de fatores realizam seu trabalho com semblante triste.

A zona de tolerância descrita por Zeithaml e Bitner (2003) configurou-se nos relatos de entrevistados descontentes com a qualidade da limpeza, por inúmeras vezes o serviço desejado ficou a quem do serviço prestado. As expectativas dos servidores principalmente em relação a limpeza dos banheiros se mostrou superior ao realizado.

O julgamento da qualidade em serviços passa por cinco dimensões conforme já relatado no referencial teórico por Lovelock e Wright (2003), que são confiabilidade, tangibilidade, sensibilidade, segurança e empatia, com as entrevistas foi possível identificar que a tangibilidade percebida pelos servidores é grande, com o uso de uniformes e equipamentos, assim a empresa terceirizada possibilita fácil identificação. Já em relação à segurança foi difícil evidenciar esse fato pois todos os pedidos devem ser feitos a apenas uma ou duas pessoas responsáveis por todos os outros trabalhadores terceirizados, assim, na maioria das vezes as informações são centralizadas. $\mathrm{O}$ aspecto confiabilidade ficou aquém do esperado já que a qualidade do serviço prestado é inferior ao contratado.

Gerir os serviços terceirizados demanda da contratante e de seus fiscais conhecimento acerca dos serviços a serem prestados, bem como planilhas de gastos, vantagens e desvantagens de se terceirizar. $\mathrm{O}$ serviço de limpeza prestado por uma empresa especializada em conservação e limpeza otimiza a manutenção de um ambiente agradável e saudável para os usuários do referido órgão. Embora existam relatos divergentes entre o que é percebido pelos funcionários e o que é entregue pela contratada, os serviços se mostraram relativamente adequados, evidenciando apropriada gestão de serviços terceirizados por parte da contratada.

Para futuros estudos, sugere-se investigar a percepção dos alunos quanto a limpeza das salas, laboratórios e banheiros 
dos prédios escolares por meio de uma abordagem quantitativa, embora não seja superior aos relatos verbais, entretanto

\section{REFERÊNCIAS}

BATESON, J. E. G; HOFFMAN, K. D. Marketing de serviços. 4. ed. Porto Alegre: Bookman, 2001. 495 p.

BRASIL. Constituição da República Federativa do Brasil, de 05 de outubro de1988. Diário Oficial da União, Brasília: 05 de out. de 1988. Disponível em <http:// http://www.planalto.gov.br/ccivil_03/con stituicao/constituicao.htm> Acesso em 12 fev. 2016.

\section{BRASIL. Instrução Normativa $n^{\circ}$ 02/2008}

do MPOG, de 30 de abril de 2008. Dispõe sobre regras e diretrizes para a contratação de serviços, continuados ou não. Disponível em:

$<$ http://www.comprasnet.gov.br/legislaca o/in/in02_30042008.htm> Acesso em: 21 fev. 2016.

BRASIL. Lei no 8.666/93, de 21 de junho de 1993. Regulamenta o art. 37, inciso XXI, da Constituição Federal, institui normas para licitações e contratos da Administração Pública e dá outras providências. Diário Oficial da União, Brasília: 21 nov. de 1993. Disponível em: < http://www.planalto.gov.br/ccivil_03/leis/ 18666cons.htm > Acesso em: 01 mar. 2016.

BRASIL. Lei no 9.491, de 09 de setembro de 1997. Altera procedimentos relativos ao Programa Nacional de Desestatização, revoga a Lei $\mathrm{n}^{\circ} \mathbf{8 . 0 3 1}$, de 12 de abril de 1990, e dá outras providências. Diário

Oficial da União, Brasília: 10 set. de 1997. investigar uma população maior abrangeria aspectos específicos do tema e possibilitaria generalizações.

Disponível em:

<http://www.planalto.gov.br/ccivil_03/lei s/L9491.htm> Acesso em: 12 nov. 2015.

BRASIL. Lei no 9.784, de 29 de janeiro de 1999. Regula o processo administrativo no âmbito da Administração Pública Federal. Diário Oficial da União, Brasília: 29 jan. de 1999. Disponível em: $<$ http://www.planalto.gov.br/ccivil_03/lei s/L9784.htm> Acesso em: 01 dez. 2013.

CAPPELLE, M. C. A.; MELO, M. C. O. L.; GONÇALVES, C. A. Análise de conteúdo e análise de discurso nas ciências sociais. Disponível em $<$ http://revista.dae.ufla.br/index.php/ora/ article/vi ew/2 51/248>. Acesso em 22 nov. 2015.

CHURCHILL JR., G. A.; PETER, J. P. Marketing: criando valor para os clientes. 2. ed. São Paulo: Saraiva, 2003. 626 p.

\section{CORREIO BRASILIENSE- AGENCIA} BRASIL. Disponível em $<$ http://www.correiobraziliense.com.br/ap p/noticia/economia/2013/03/01/internas_e conomia,352273/setor-de-servicos-edestaque-da-economia-brasileira-indicaibge.shtml>. Acesso em 18 nov. 2015.

ELEUTÉRIO, S. A. V.; SOUZA, M. C. A. F. Qualidade na prestação de serviços: uma avaliação com clientes internos. Caderno de Pesquisa em Administração, São Paulo, v.9, no 3, jul./set. 2002, p. 53-64. 
GARCIA, R. C. Avaliação na qualidade percebida dos serviços de conservação e limpeza do CEFET-MG. 2010, 100f.

Dissertação (Mestrado em Administração) - Faculdade Novos Horizontes, Belo Horizonte. 2010.

GIOSA, L. A. Terceirização: uma abordagem estratégica. 5. ed. São Paulo Ed. Pioneira, 1997. 145p.

GRÖNROOS, C. Marketing, gerenciamento e serviços: Tradução de Arlete Simile Marques. 2. Ed. Rio de Janeiro: Elsevier, 2004. 4. reimpressão. 482p.

HOFFMAN, K. D. et al. Princípios de Marketing de serviços: conceitos, estratégias e casos. São Paulo. 3 ed. Cengage Learning: 2009. 600 p.

KOTLER, P. Marketing essencial: conceitos, estratégias e casos. 2. ed. São Paulo: Prentice Hall, 2005. 406 p.

KOTLER, P.; HAYES,T.; BLOMM, P. N. Marketing de Serviços profissionais: estratégias inovadoras para impulsionar sua atividade, sua imagem e seus lucros. 2. ed. São Paulo: Manole, 2002.

LOVELOCK, C. H; WRIGHT, L. Serviços: marketing e gestão. São Paulo: Saraiva, 2003. 416p.

MAINARDES, E. W.; LOURENÇO, L.; TONTINI, G. Percepções dos Conceitos de Qualidade e Gestão pela Qualidade Total: estudo de caso na universidade. GESTÃO.Org - Revista Eletrônica de Gestão Organizacional, v. 8, n. 2, p. 279-297, 2010.
MARCELINO, P. R. Afinal o que é terceirização: em busca de ferramentas de análise e ação política. Revista da Faculdade de Ciências e Tecnologia da Unesp, v.8, n 2, dez. 2007, p. 55-71.

SILVA, C. R. et al. Ergonomia: um Estudo sobre Sua Influência na

Produtividade. Revista de Gestão, v. 16, n. 4, art. 5, p. 61-75, out./dez 2009.

SILVA, P. P. Terceirização nos serviços públicos. Revista do Curso de Direito da UNIFACS, 2011.

SOUZA, E. C.; MEIRA, J. V. S.; MASKE, D. C. A medição da qualidade dos serviços prestados em hotéis de Balneário Camboriú, SC: Uma aplicação do modelo SERVQUAL. Rosa dos Ventos, v. 4, n. 4, p. 544-555, 2012.

SILVA, C. R.; SILVA, M. A. C.; SILVA, S. R.; SOUZA, J. C. C.; SANTOS, S. D. D. Ergonomia: um Estudo sobre Sua Influência na Produtividade. Revista de Gestão,

STEFANO, N. M. Uma avaliação empírica e aplicação da escala Servqual e do índice Pasc para a mensuração da qualidade dos serviços. Revista de Economia e Administração, v. 8, n. 2, p. 181-196, abr/jun. 2009.

ZEITHALM, V. A; PARASURAMAN, A, BERRY., L. L. Delivering Quality Service - Balancing Customer Perceptions and a Expectations. New York. The Free Press, 1990, 226 p. 